\title{
The effect of repetitive transcranial magnetic stimulation on dorsolateral prefrontal glutamate in youth with treatment-resistant depression
}

\author{
S Pradhan ${ }^{1 *}$, A Kirton $^{2}$, G MacQueen ${ }^{2}$, F MacMaster $^{2}$ \\ From International Conference for Healthcare and Medical Students (ICHAMS) 2013 \\ Dublin, Ireland. 11-12 October 2013
}

\section{Background}

Major Depressive Disorder (MDD) is a debilitating psychiatric disorder characterized by feelings of low selfworth, loss of interest and suicidal thoughts. An estimated 350 million people are affected worldwide, $15 \%$ being adolescents. Repetitive transcranial magnetic stimulation (rTMS) is a non-invasive intervention that modulates cortical excitability by inducing electric currents in neurons by administering pulsating magnetic fields to the scalp. Studies have shown the left dorsolateral prefrontal cortex (DLPFC) to be implicated in positive effects on emotion, and glutamate/Glx levels to be decreased in MDD patients. In adults, rTMS has been shown to significantly improve mood, decrease Hamilton Depression Scores and increase glutamate, glutamine and choline levels in the DLPFC. We hypothesize an increase in DLPFC glutamate levels following treatment.

\section{Methods}

Eleven treatment-resistant MDD patients (4 females and 7 males, ages 15-21) were recruited and clinically assessed using the Hamilton Depression/Anxiety Rating Scale and the Children's Depression Rating Scale at baseline, and during each week of treatment for three weeks. Participants also underwent baseline and post-treatment MRI scans. Magnetic resonance spectroscopy was used to measure glutamate levels and data was analysed using the LC model method. TMS treatments were performed daily for three weeks and treatment response was defined as $\geq 50 \%$ decrease in baseline Ham-D rating scale.

\section{Results}

In general, rTMS treatments were well tolerated, however some patients described minor side effects of mild headaches and scalp discomfort. Seven patients were treatment responders who showed symptom improvement, a $62 \%$ decrease in Ham-D scores from $25.43( \pm 7.85)$ to 9.57 $( \pm 1.51)$ and a $30 \%$ decrease in CDRS scores from 74.43 $( \pm 11.04)$ to $52.14( \pm 8.99)$. Ham-A scores decreased $78 \%$ from $23.86( \pm 9.65)$ to $5.29( \pm 3.55)$. In the left DLPFC, treatment responder glutamine levels increased by $5 \%$ and Glx levels increased by $10 \%$ in the DLPFC. Responders also showed lower baseline glutamate levels at $8.73( \pm 1.21)$ $\mathrm{mmol} / \mathrm{kg}$-wet-weight, which increased by $12 \%$ to 9.77 $( \pm 1.18)$ following treatment. Interestingly, non-responders had higher baseline glutamate levels at $11.87( \pm 0.47)$ and levels decreased by $9 \%$ to $10.75( \pm 0.13)$.

\section{Conclusions}

These findings are consistent with previous literature. Evidence of increases in excitatory neurotransmitter levels in the DLPFC and alleviation of symptoms following treatment indicate that rTMS exerts anti-depressant effects and can be pursued as a safe and effective therapy for adolescent MDD.

\section{Authors' details \\ ${ }^{1}$ Royal College of Surgeons in Ireland, 123 St. Stephen's Green, Dublin 2, Ireland. ${ }^{2}$ Department of Psychiatry and Clinical Neurosciences, University of Calgary, 2500 University Dr. NW Calgary, Alberta, Canada.T2N 1N4.}

Published: 14 January 2015

${ }^{1}$ Royal College of Surgeons in Ireland, 123 St. Stephen's Green, Dublin 2,

Ireland

Full list of author information is available at the end of the article 
doi:10.1186/1753-6561-9-S1-A9

Cite this article as: Pradhan et al:: The effect of repetitive transcranial magnetic stimulation on dorsolateral prefrontal glutamate in youth with treatment-resistant depression. BMC Proceedings 2015 9(Suppl 1):A9.

Submit your next manuscript to BioMed Central and take full advantage of:

- Convenient online submission

- Thorough peer review

- No space constraints or color figure charges

- Immediate publication on acceptance

- Inclusion in PubMed, CAS, Scopus and Google Scholar

- Research which is freely available for redistribution

Submit your manuscript at www.biomedcentral.com/submit 